\title{
Response to the letter regarding the article "Predictive value of admission red cell distribution width-platelet ratio for no-reflow phenomenon in acute ST segment elevation myocardial infarction undergoing primary percutaneous coronary intervention"
}

We deeply appreciate valuable comments of the author [1] on our clinical study entitled "Predictive value of admission red cell distribution widthplatelet ratio for no-reflow phenomenon in acute ST segment elevation myocardial infarction undergoing primary percutaneous coronary intervention" [2]. Although providing epicardial coronary vessel patency, primary percutaneous coronary intervention ( $\mathrm{pPCI}$ ) may not achieve restoration of optimal myocardial reperfusion within the myocardial tissue, a failure at the microvascular level known as no-reflow (NR) [3]. Despite achievement of optimal epicardial coronary flow in the majority of patients treated for ST segment elevation myocardial infarction (STEMI) by pPCI, myocardial NR is a commonly encountered phenomenon occurring in 5\% to $50 \%$ of those patients [3]. The 'no-reflow' phenomenon in patients with STEMI is associated with a worse prognosis at short- and long-term follow-up periods [4]. Whatever the diagnostic method used, one should take into consideration the dynamic nature of NR. Indeed, NR may persist up to $48 \mathrm{~h}$ after reperfusion, although this timeframe is somewhat hypothetical [4]. On the other hand, a transient slowing of myocardial blood flow in the infarcted area could not be analyzed as easily as a fixed obstruction of the myocardial microvasculature.

In the previously published clinical studies, NR has often been defined as a Thrombolysis in Myocardial Infarction (TIMI) flow grade $\leq 2$ in the absence of macrovascular obstruction [5-11]. Concordantly, NR was defined as TIMI flow grades 0-2 (no-reflow group) and reflow was defined as TIMI 3 flow grade in our study [12]. However, microvascular perfusion may also be reduced in patients with TIMI flow grade 3 [13]. TIMI flow assessment on classical coronary angiography is a simple and easily obtained method, although it has some limitations regarding to sensitivity and specificity for the assessment of NR. Indeed, capillary blood flow is not measured directly by angiography, and a significant proportion of TIMI grade 3 flow patients actually present with NR [14]. Therefore, other angiographic measures that have been developed to assess microvascular perfusion include the TIMI frame count and myocardial blush grade (MBG) [15]. MBG is another newly developed angiographic imaging technique for assessing myocardial microvasculature and tissue reflow [13]. With this method cardiologists can assess the myocardial tissue opacification intensity with longer angiographic runs, performed until the venous phase of contrast passage. According to visual or computerized signal intensity automatic assessment, myocardial "blush" is graded according to a scale with four intensity grades: $0-$ no myocardial blush; 1 - minimal myocardial blush or contrast density; 2 - moderate myocardial blush or contrast density, but less than that obtained during angiography of a contralateral non-infarct-related coronary artery; and 3 - normal myocardial blush or contrast density, similar to that obtained during angiography of a contralateral non-infarctrelated coronary artery. However, this very low contrast-to-noise imaging method of myocardial tissue opacification has the same limitations as the angiographic TIMI scale [16]. More importantly, Van't Hof et al. [13] demonstrated relatively high inter- and intra-observer variabilities of MBG in patients with STEMI (3\% and 10\%, respectively).

On the other hand, timing of angiography may be too early to assess myocardial reperfusion injuries and other complex phenomena occurring in the hours and days after reperfusion. Therefore, post-PCI TIMI flow or MBG are not necessarily predictive of the presence of microvascular obstruction (MVO) as detected by cardiac magnetic 
resonance (CMR) [16]. CMR represents the most sensitive and specific method of assessment for NR [4]. Contrast enhanced CMR can be able to identify the lack of myocardial reperfusion after STEMI. CMR also allows a complete and accurate assessment of left ventricular status in patients after STEMI. Moreover, it is able to assess both functional and structural abnormalities of coronary microvasculature through MVO study, in contrast to conventional angiography providing a functional assessment regarding myocardial blood flow. Although a grade $3 \mathrm{MBG}$ or TIMI flow indicate a good prognosis at population level, up to $60 \%$ of STEMI patients with optimal angiographic reperfusion indices (MBG and TIMI flow $=3$ ) show NR on CMR at the following $72 \mathrm{~h}$ on an individual basis [17].

In addition to conventional angiographic methods, coronary Doppler flow wire can be used to assess NR. Doppler flow measurements reveal a characteristic pattern of both systolic retrograde flow and rapid deceleration of diastolic flow in vessels with NR [17].

In conclusion, although MBG is found to be superior to TIMI flow grade for the detection of NR, it has some major limitations including very low contrast-to-noise imaging method of myocardial tissue opacification and relatively high intra- and inter-observer variabilities. On the other hand, we are convinced that TIMI flow grade assessment is more practical and swift method for NR diagnosis in catheterization laboratory when considering critical time window for the treatment.

\section{Conflict of interest: None declared}

\section{References}

1. İşcen S. Myocardial blush grade and Thrombolysis in Myocardial Infarction flow grade in ST segment elevation myocardial infarction. Cardiol J, 2016; 23: 588. doi: 10.5603/CJ.2016.0082.

2. Celık T, Balta S, Demır M et al. Predictive value of admission red cell distribution width-platelet ratio for no-reflow phenomenon in acute ST segment elevation myocardial infarction undergoing primary percutaneous coronary intervention. Cardiol J, 2016; 23: 84-92. doi: 10.5603/CJ.a2015.0070.

3. Bouleti C, Mewton N, Germain S. The no-reflow phenomenon: State of the art. Arch Cardiovasc Dis, 2015; 108: 661-674. doi: 10.1016/j.acvd.2015.09.006.

4. Durante A, Camici PG. Novel insights into an "old" phenomenon: the no reflow. Int J Cardiol, 2015; 187: 273-280. doi: 10.1016/j. ijcard.2015.03.359.
5. Piana RN, Paik GY, Moscucci M et al. Incidence and treatment of "no-reflow" after percutaneous coronary intervention. Circulation, 1994; 89: 2514-2518.

6. Morishima I, Sone T, Okumura K et al. Angiographic no-reflow phenomenon as a predictor of adverse long-term outcome in patients treated with percutaneous transluminal coronary angioplasty for first acute myocardial infarction. J Am Coll Cardiol, 2000; 36: 1202-1209.

7. Celik T, Balta S, Ozturk C et al. Predictors of no-reflow phenomenon in young patients with acute ST-segment elevation myocardial infarction undergoing primary percutaneous coronary intervention. Angiology, 2015. doi: 10.1177/0003319715605977.

8. Celik T, Kaya MG, Akpek M et al. Predictive value of admission platelet volume indices for in-hospital major adverse cardiovascular events in acute ST-segment elevation myocardial infarction. Angiology, 2015; 66: 155-162. doi:10.1177/0003319713513493.

9. Celik T, Kaya MG, Akpek M et al. Does Serum Bilirubin level on admission predict TIMI flow grade and in-hospital MACE in patients with STEMI undergoing primary PCI. Angiology, 2014; 65: 198-204. doi: 10.1177/0003319712474948.

10. Akpek M, Kaya MG, Lam YY et al. Relation of neutrophil/lymphocyte ratio to coronary flow to in-hospital major adverse cardiac events in patients with ST-elevated myocardial infarction undergoing primary coronary intervention. Am J Cardiol, 2012; 110: 621-627. doi: 10.1016/j.amjcard.2012.04.041.

11. Celik T, Iyisoy A, Yuksel CU et al. Impact of admission glomerular filtration rate on the development of poor myocardial perfusion after primary percutaneous intervention in patients with acute myocardial infarction. Coron Artery Dis, 2008; 19: 543-549. doi: 10.1097/MCA.0b013e3283108fef.

12. Celık T, Balta S, Demır M et al. Predictive value of admission red cell distribution width-platelet ratio for no-reflow phenomenon in acute ST segment elevation myocardial infarction undergoing primary percutaneous coronary intervention. Cardiol J, 2016; 23: 84-92. doi: 10.5603/CJ.a2015.0070.

13. van't Hof AW, Liem A, Suryapranata H, Hoorntje JC, de Boer MJ, Zijlstra F. Angiographic assessment of myocardial reperfusion in patients treated with primary angioplasty for acute myocardial infarction: myocardial blush grade. Zwolle Myocardial Infarction Study Group. Circulation, 1998; 97: 2302-2306.

14. Henriques JPS, Zijlstra F, van't Hof AWJ et al. Angiographic assessment of reperfusion in acute myocardial infarction by myocardial blush grade. Circulation, 2003; 107: 2115-2119. doi: 10.1161/01.CIR.0000065221.06430.ED.

15. Haager PK, Christott P, Heussen N, Lepper W, Hanrath P, Hoffmann R. Prediction of clinical outcome after mechanical revascularization in acute myocardial infarction by markers of myocardial reperfusion. J Am Coll Cardiol, 2003; 41: 532-538.

16. Vicente J, Mewton N, Croisille P et al. Comparison of the angiographic myocardial blush grade with delayed-enhanced cardiac magnetic resonance for the assessment of microvascular obstruction in acute myocardial infarctions. Catheter Cardiovasc Interv, 2009; 74: 1000-1007. doi:10.1002/ccd.22157.

17. Nijveldt R, Hofman MBM, Hirsch A et al. Assessment of microvascular obstruction and prediction of short-term remodeling after acute myocardial infarction: cardiac MR imaging study. Radiology, 2009; 250: 363-370. doi: 10.1148/radiol.2502080739.

18. Furber AP, Prunier F, Nguyen HCP, Boulet S, Delépine S, Geslin P. Coronary blood flow assessment after successful angioplasty for acute myocardial infarction predicts the risk of long-term cardiac events. Circulation, 2004; 110: 3527-3533. doi: 10.1161/01. CIR.0000148686.95696.1E.

Turgay Celik, Cengiz Ozturk, Sevket Balta, A. Osman Yildirim

Department of Cardiology, School of Medicine, Gulhane Military Medical Academy, 06018 Etlik-Ankara, Turkey,

tel: +90-312-3044268, fax: +90-312-3044250, e-mail: benturgay@yahoo.com 